\title{
Memory for Extinction of Conditioned Fear Is Long-lasting and Persists Following Spontaneous Recovery
}

\author{
Gregory J. Quirk \\ Department of Physiology, Ponce School of Medicine, Ponce, Puerto Rico, 00732
}

\begin{abstract}
Conditioned fear responses to a tone paired with footshock rapidly extinguish when the tone is presented in the absence of the shock. Rather than erase conditioning, extinction is thought to involve the formation of new memory. In support of this, extinguished freezing spontaneously recovers with the passage of time. It is not known, however, how long extinction memory lasts or whether extinction interferes with consolidation of conditioning if given on the same day. To address this, we gave rats 7 trials of auditory fear conditioning followed $1 \mathrm{~h}$ later by 20 extinction trials, and tested for spontaneous recovery after a delay of $0,1,2,4,6$, 10 , or $14 \mathrm{~d}$. Conditioned freezing to the tone gradually recovered with time to reach $100 \%$ by day 10 . No-extinction controls indicated that the increase in freezing with time was not owing to incubation of conditioning memory. Complete spontaneous recovery indicates that extinction training given $1 \mathrm{~h}$ after conditioning does not interfere with the consolidation of conditioning memory. Despite complete recovery of freezing, rats showed savings in their rate of re-extinction, indicating persistence of extinction memory. These data support the idea that conditioning and extinction of fear are learned by independent systems, each able to retain a long-term memory.
\end{abstract}

A useful paradigm for studying long-term memory in animals is Pavlovian fear conditioning, in which a conditioned stimulus (CS), such as a tone, is paired with an aversive unconditioned stimulus (US), such as electric shock. After several such pairings, the tone elicits autonomic and behavioral fear responses such as freezing (Blanchard and Blanchard 1972; Fanselow 1980). The association between the tone and shock is robust and long lasting, and it has been suggested that conditioned fear associations are indelible (LeDoux et al. 1989; Ohman and Mineka 2001; Gale and Fanselow 2002). If true, conditioned fear associations could help an animal detect and avoid previously encountered threats throughout its life.

Once acquired, however, conditioned fear associations are not always expressed. Repeated presentation of the CS in the absence of the US causes conditioned responses to extinguish. For example, a single session of un-reinforced tones is sufficient to extinguish conditioned freezing levels from 70\% to near 0 (Quirk et al. 2000; Santini et al. 2001; Herry and Garcia 2002). In his classic studies with appetitive conditioning, Pavlov (1927) demonstrated that conditioned responses that had been extinguished would spontaneously recover with the passage of time. He concluded that extinction does not erase the conditioned association but inhibits the conditioned response. If true, extinction memory is separate from conditioning memory (Konorski

E-MAIL gjquirk@yahoo.com; FAX (787) 844-1980. Article and publication are at http://www.learnmem.org/cgi/doi/ $10.1101 / \mathrm{lm} .49602$.
1967). More recent behavioral work has supported this idea for extinction of conditioned fear (Rescorla and Heth 1975; Bouton and King 1983; Herry and Garcia 2002).

Spontaneous recovery of conditioned responses after extinction raises several important questions regarding extinction memory that remain unanswered for conditioned fear: (1) For how long is extinction memory expressed, and what is the time course of spontaneous recovery; (2) does conditioned fear spontaneously recover to $100 \%$ with sufficient time, or is conditioning partially erased by extinction; and (3) does the passage of time erase extinction memory, or does extinction memory persist despite spontaneous recovery?

We addressed these issues using auditory fear conditioning. Rats were given conditioning trials followed by extinction trials in a single day, and then tested for spontaneous recovery after a variable delay. We have previously shown that extinction memory lasts $48 \mathrm{~h}$ in this paradigm (Santini et al. 2001), but longer intervals were not tested. Here we measure spontaneous recovery at various time points up to $14 \mathrm{~d}$. In addition, we examined the rate of re-extinction for evidence of persistent extinction memory after spontaneous recovery. A preliminary report of these findings has appeared (Milad et al. 2001).

\section{RESULTS}

Figure 1 shows the protocol of the experiment. On do, rats were given 7 trials of auditory fear conditioning, followed $1 \mathrm{~h}$ later by 20 extinction trials. They were then tested for

LEARNING \& MEMORY 9:402-407 @ 2002 by Cold Spring Harbor Laboratory Press ISSN1072-0502/02 \$5.00

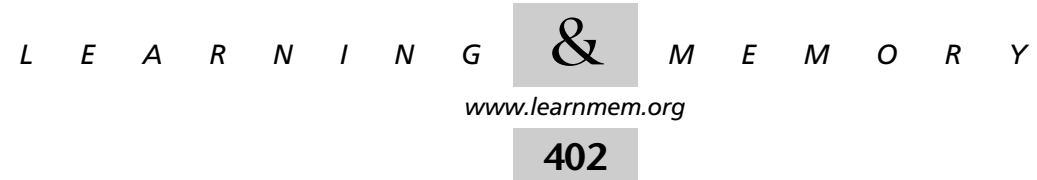




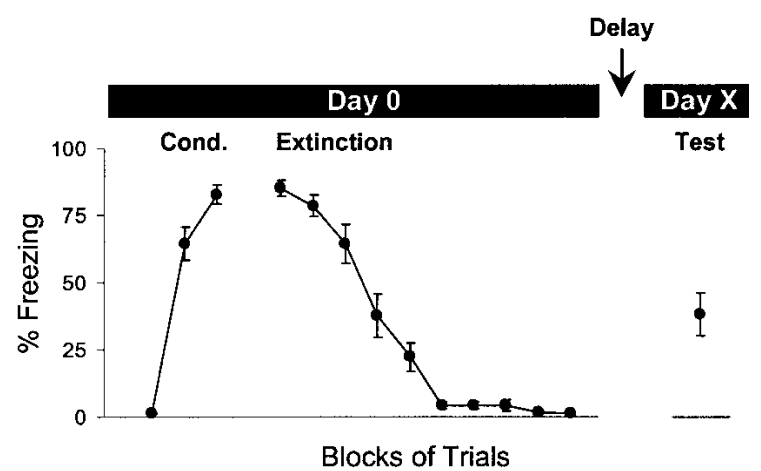

Figure 1 Fear conditioning protocol. On day $0(\mathrm{~d} 0)$, all rats were given seven conditioning trials (tone-shock) followed $1 \mathrm{~h}$ later by 20 extinction trials (tone alone). The intertrial interval averaged 4 min. After a variable number of days, rats were given additional extinction trials to test for spontaneous recovery of freezing to the tone. Data are shown for group $\mathrm{d} 1$, which was tested $1 \mathrm{~d}$ after extinction. Trial blocks consist of two trials. In this and subsequent figures, error bars show \pm SEM.

spontaneous recovery of freezing to tones after a variable delay of $0,1,2,4,6,10$, or $14 \mathrm{~d}$, with separate groups at each time point. On d0, all groups acquired similar amounts of conditioned freezing to the tone. Figure $2 \mathrm{~A}$ shows the acquired freezing for each group. The average freezing level across groups was $81 \%$ (range, $72 \%-87 \%$ ). After 20 extinction trials, freezing diminished to negligible levels, averaging only $4 \%$ (see Fig. 2B). The rate of extinction was similar across groups (see inset of Fig. 2). The number of trials rats spent at floor (defined as number of consecutive trials with $<5$ sec freezing) averaged 10 trials (d0, 9; d1, 10; d2, 11; d4, $10 ; \mathrm{d} 6,9 ; \mathrm{d} 10,9 ; \mathrm{d} 14,12)$. Thus, the level of extinction in all groups was equivalent.

On the test day, the amount of conditioned freezing that was recovered increased with increasing post-extinction delay. Figure $2 \mathrm{C}$ shows the percent rebound of freezing, defined as the percent of acquired freezing from do recovered on the test day. One-way ANOVA of rebound values showed a highly significant main effect of group $\left(\mathrm{F}_{[6,53]}=11.53, P<0.001\right.$ ). A rebound value of $100 \%$ (indicating no expression of extinction) was outside the $95 \%$ confidence interval for groups $0 d, 1 d, 2 d, 4 d$, and $6 d$, but not for groups $\mathrm{d} 10$ and $\mathrm{d} 14$. Thus, significant extinction memory was expressed through $6 \mathrm{~d}$, but not after 10 or 14 d. Histograms of individual rebound values at each time point are shown in Figure 3, which clearly illustrates the gradual shift toward $100 \%$ with the passage of time.

The increase in freezing was not owing to incubation of the conditioning memory. No-extinction controls tested either 1 or $14 \mathrm{~d}$ after conditioning showed 126\% and 104\% rebound, respectively. This difference was not significant ( $\mathrm{t}=1.75, \mathrm{df}=17, P>0.05)$, indicating that the passage of time alone did not increase the expression of conditioned freezing. Thus, the increased freezing in the extinction groups is caused most likely by reduced expression of ex- tinction memory rather than by increased expression of conditioning memory.

Because conditioning and extinction were given in the same chamber, conditioning to the context may have contributed to the increase in freezing to the tone with time. However, we observed little evidence of contextual fear conditioning in this experiment. Rats exhibited no freezing during the intertrial intervals of the extinction sessions, either on $\mathrm{d} 0$ or on the test day. The rate of spontaneous bar-pressing for food, a more sensitive indicator of conditioned fear (Mast et al. 1982), also showed no evidence of context conditioning. On average, rats spontaneously pressed at 20/min (+1.6 SE) prior to conditioning, and 18/ min (+0.9 SE) $1 \mathrm{~h}$ after conditioning (just prior to the first
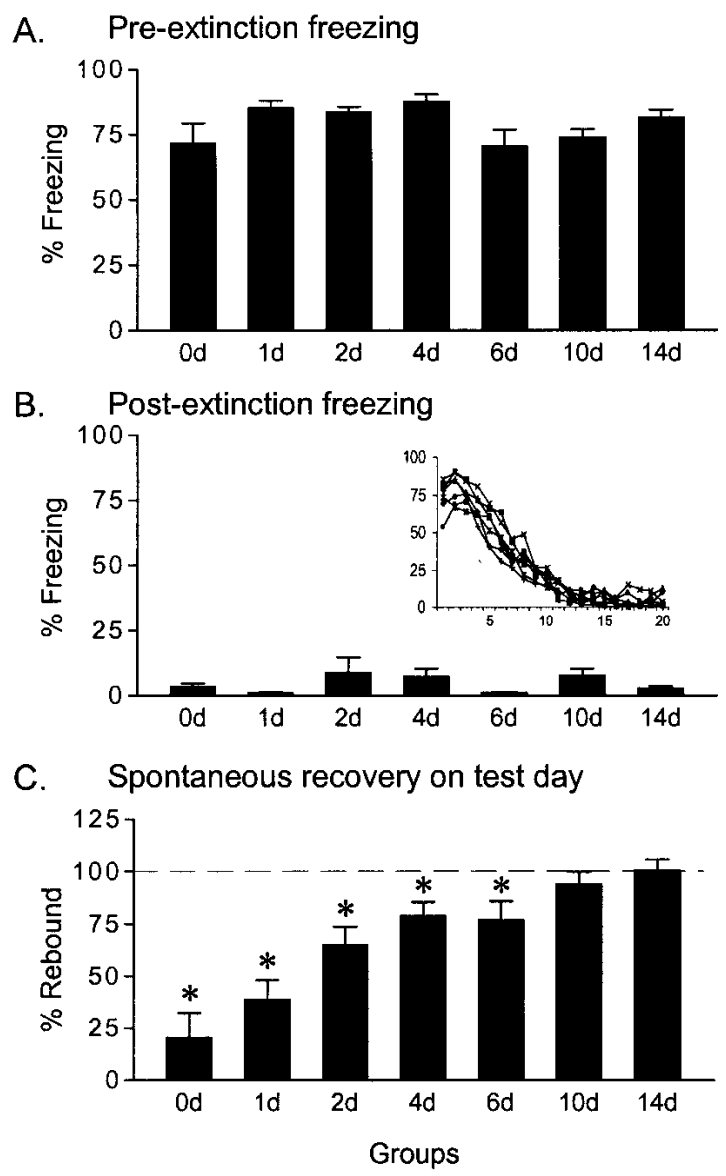

Figure 2 Freezing to the tone at three time points: (A) Pre-extinction on day 0 (d0; tones $1-2)$; (B) post-extinction on $\mathrm{d} 0$ (tones 19-20); and (C) spontaneous recovery on the test day (tones 1-2). The $x$-axis indicates experimental groups, which were tested either $1,2,4,6,10$, or $14 \mathrm{~d}$ after extinction. The degree of spontaneous recovery was expressed as percent rebound, which is the percent of conditioned freezing acquired on do recovered on the test day. Asterisks indicate significant difference from 100\% $(p<0.05)$, demonstrating significant expression of extinction memory. Extinction was expressed through $6 \mathrm{~d}$, but not at 10 or $14 \mathrm{~d}$. Inset: Individual extinction curves for each group across the 20 extinction trials on $\mathrm{d} 0$.

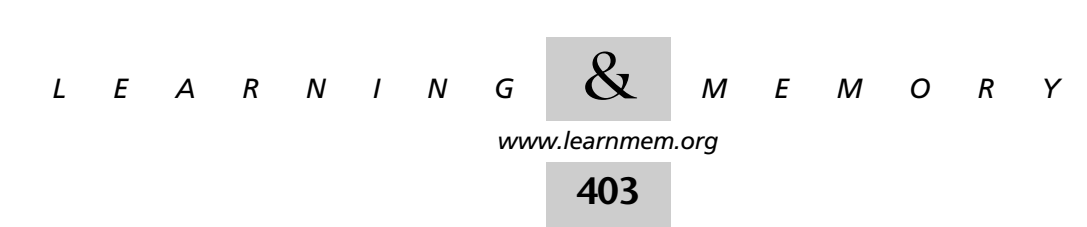




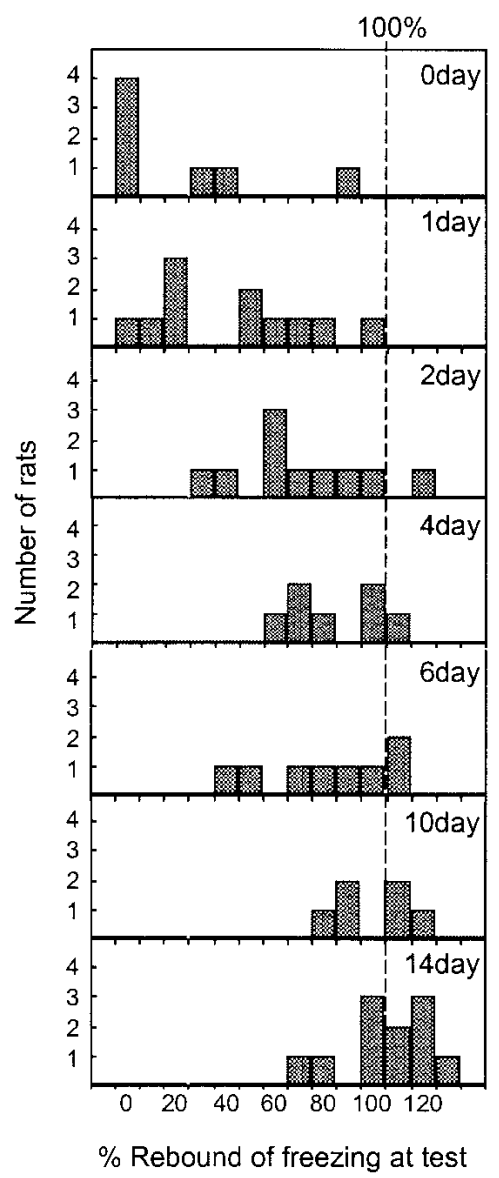

Figure 3 Distribution of individual rebound values for each group on the test day. Rebound of freezing (spontaneous recovery) gradually shifted toward $100 \%$ with the passage of time.

extinction tone). On the test day (just prior to the first extinction tone), the spontaneous press rate was maintained at $19 / \mathrm{min}(+2.0 \mathrm{SE})$. ANOVA showed no significant difference between these press rates $\left(F_{[2,10]}=0.17\right.$, $P>0.8$ ). For individual groups, the rate of pressing at the start of the test day never fell significantly below $100 \%$ of the rate on $\mathrm{d} 0(\mathrm{~d} 1,97 \%$; $2,110 \%$; $4,153 \%$; $6,98 \%$; 110 , $87 \%$; $14,83 \%)$. Factors that might account for the absence of context conditioning in our experiments were that animals had extensive experience with the chambers prior to the start of the experiments, and were motivated to press for food throughout. Thus, it is unlikely that the increase in freezing to tones with time could be attributed to increasing fear to the context, because no context-induced freezing or suppression of bar-pressing was observed.

No extinction memory was expressed $14 \mathrm{~d}$ after extinction, as indicated by the $100 \%$ spontaneous recovery of freezing to the tone. Does this mean that extinction was completely forgotten with time? We compared the rates of original extinction (d0) and re-extinction (d14) for evidence of savings (see Fig. 4) . Despite complete recovery of con- ditioned freezing on $\mathrm{d} 14$, rats re-extinguished significantly faster than they extinguished on $\mathrm{d} 0$, indicating retention of extinction memory. Comparison of extinction and re-extinction curves with ANOVA showed a significant effect of group $\left(\mathrm{F}_{[1,22]}=4.4, P<0.05\right)$, trial block $\left(\mathrm{F}_{[6,132]}=145.1\right.$, $P<0.001)$, and interaction $\left(\mathrm{F}_{[6,132]}=3.8, P<0.01\right)$. Posthoc tests revealed that re-extinction was significantly faster than original extinction in trial blocks 2 and $3(P<0.05)$. These findings indicate that at least some component of the extinction memory was intact at $\mathrm{d} 14$, despite complete spontaneous recovery.

\section{DISCUSSION}

We have measured the rate of spontaneous recovery of conditioned fear to a tone after extinction. After a single extinction session, conditioned freezing gradually recovered over a period of days to reach $100 \%$ by d10. This increase in freezing with time was not owing to incubation of the conditioning memory, because no such increase was observed in extinction-naïve controls. We conclude that the increased freezing was caused by decreased expression of extinction over time.

The recovery of conditioned freezing to $100 \%$ demonstrates that conditioning memory was not erased (even partially) by extinction training. This does not agree with a previous suggestion that extinction training given on the same day as fear conditioning can disrupt the consolidation of conditioning memory (Cain and Barad 2000). In this view, freezing is low the day after extinction because conditioning memory is prevented from being properly consolidated. If true, conditioning memory would not be expected to fully recover with the passage of time as we observed. Our data indicate, instead, that learning extinction does not induce "unlearning" of conditioning, even if both are given on the same day. However, the ability of extinction training

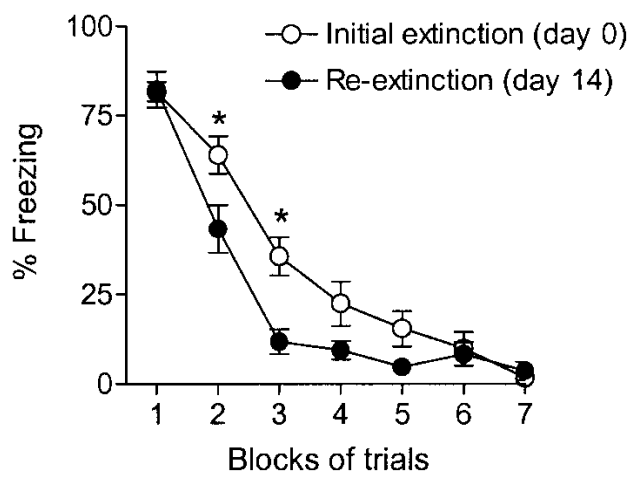

Figure 4 Savings in the rate of re-extinction. Extinction curves for original extinction on day 0 (d0; empty circles) and re-extinction on d14 (filled circles) are shown. Despite 100\% spontaneous recovery, rats reextinguished significantly faster than they extinguished originally, indicating that some component of extinction memory was preserved. Asterisks indicate significant post-hoc comparisons $(p<0.05)$ following significant main effects of group and trial in ANOVA (see text).

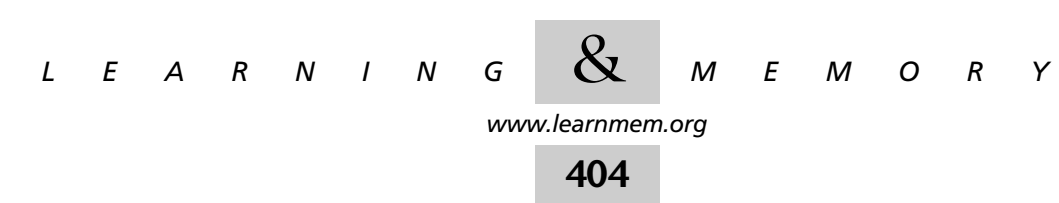


to affect consolidation of acquisition may depend on the interval between acquisition and extinction training, and on the number of extinction trials. We examined only a 1-h acquisition-extinction interval in the present study; other intervals might reveal a window of vulnerability for consolidation of conditioning (Cain and Barad 2000). Measuring the maximum level of spontaneous recovery, as in the present study, could be used in future studies to assess the strength of conditioning memory after extinction.

Extinction memory was expressed for up to $6 \mathrm{~d}$ as evidenced by low rebound of freezing. Similar reports of extinction of conditioned fear lasting through $10 \mathrm{~d}$ have recently appeared (Lattal and Abel 2001; Herry and Garcia 2002), demonstrating that extinction of conditioned fear is long-term memory. Indeed, extinction memory was still present even after $14 \mathrm{~d}$, as evidenced by savings in the rate of re-extinction. The persistence of extinction memory after spontaneous recovery has been reported for appetitive conditioning (Bouton et al. 1993). Therefore, in the same way that extinction does not erase conditioning memory, neither does the passage of time erase extinction memory, even though full spontaneous recovery occurs. Our data support the idea of Bouton (1991) that extinction and conditioning are stored as separate memories, both of which are available after extinction.

If both conditioning (CS-US) and extinction (CS-no US) associations are simultaneously present in the brain, which determines the behavioral response to the CS? The expression of conditioned freezing at any given moment appears to be governed by context. It is well established that extinguished freezing is renewed when animals are placed in a context other than the one in which extinction occurred (Bouton and King 1983). Bouton and coworkers have put forward a model in which contextual inputs gate retrieval of either conditioning (CS-US) or extinction (CS-no US) associations (Bouton and King 1983; Bouton 1994). Although spontaneous recovery does not involve an explicit change of context, Bouton (1993) has suggested that spontaneous recovery may be an example of renewal, because the passage of time alters a "temporal extinction context." Thus, spontaneous recovery of conditioned fear represents a failure to retrieve extinction memory rather than a loss of extinction memory. Our observation that extinction memory persists despite spontaneous recovery supports the view that spontaneous recovery is a deficit in retrieval of extinction, rather than loss of extinction memory itself.

What brain structures learn extinction? Several lines of evidence indicate that extinction learning involves the neocortex. Lesions of sensory cortices have been shown to block extinction of conditioned fear (LeDoux et al. 1989; Teich et al. 1989). More recent work indicates that the medial prefrontal cortex (mPFC) plays a key role. Lesions of the ventral mPFC interfere with extinction of conditioned fear without affecting conditioning (Morgan et al. 1993;
Morrow et al. 1999; Quirk et al. 2000, but see Gewirtz et al. 1997). Using an experimental design identical to the present study, we recently showed that rats with lesions of ventral $\mathrm{mPFC}$ (particularly the infralimbic area) extinguished to normal levels on d0, but recovered $86 \%$ of freezing to the tone the following day (Quirk et al. 2000). The high recovery in lesioned animals was not significantly different from control rats that never received extinction on d0. This pattern of results indicates that vmPFC is not necessary for short-term (within-session) memory of extinction but may be necessary for consolidation of extinction leading to stable long-term memory.

Recent physiological data parallel these lesion findings. Twenty-four hours after extinction training when rats are recalling extinction, vmPFC evoked potentials (Herry et al. 1999), and tone responses of infralimbic neurons (Milad and Quirk 2002) are potentiated. This indicates that consolidation of extinction learning is a plastic process that potentiates auditory inputs to vmPFC. Two possible candidates are the auditory association cortex (Quirk et al. 1997) and the basolateral amygdala (McDonald 1991), both of which communicate tone information to the prefrontal cortex. The amygdala seems particularly important for extinction, as microinjection of NMDA antagonists (Falls et al. 1992; Lee and Kim 1998) or agonists (Walker et al. 2002) inhibit or facilitate extinction of conditioned fear, respectively. Thus, projections from the amygdala to the vmPFC likely play a role in establishing long-term extinction memory.

Lesions of the amygdala have enduring effects on the acquisition and expression of conditioned fear (Maren 2000), indicating that it is a storage site of fear associations in auditory fear conditioning (Quirk et al. 1995; Fendt and Fanselow 1999; LeDoux 2000; Walker and Davis 2002). Projections from the infralimbic cortex to the amygdala are robust (McDonald et al. 1996; Fisk and Wyss 2000) and have been shown to inhibit transmission within the amygdala (Rosenkranz and Grace 2002). Thus, extinction may reduce the expression of fear by potentiating the inhibitory effects of infralimbic cortex on the amygdala, especially central nucleus output neurons (Royer and Pare 2002).

In summary, we have shown that extinguished freezing to a tone CS spontaneously recovers to full strength after 10 d. Despite complete recovery, extinction memory can still be observed in the rate of re-extinction. Together with other studies, these findings indicate that conditioning and extinction of fear are stored as separate memories in separate structures (perhaps the amygdala and medial prefrontal cortex, respectively). Spontaneous recovery of extinguished fear presents a challenge to clinicians who use extinction therapy to treat phobias and other anxiety disorders (Rodriguez et al. 1999). A more complete understanding of the neural circuits that learn and store extinction memory should lead to more effective treatments for anxiety disorders.

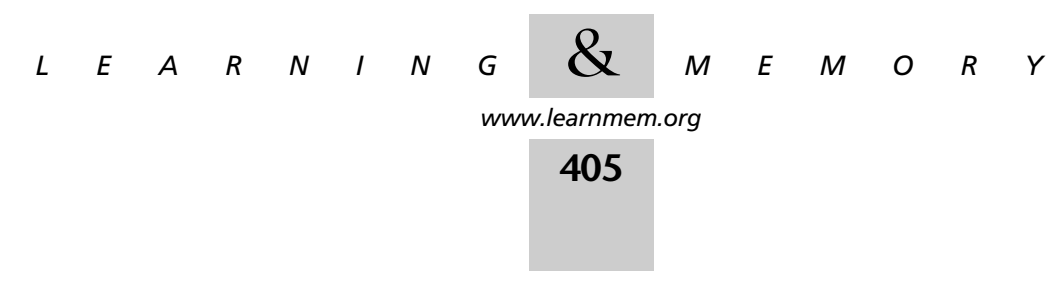




\section{MATERIALS AND METHODS}

The procedures used were approved by the Institution Animal Care and Use Committee (IACUC) of Ponce School of Medicine in compliance with National Institutes of Health (NIH) guidelines for the care and use of laboratory animals (publication no. DHHS NIH 86-23). Male Sprague-Dawley rats, weighing $\sim 300 \mathrm{~g}$, were individually housed in transparent polyethylene cages inside a negativepressure clean room (Colorado Clean Room, Ft. Collins, CO). Food was restricted to $15 \mathrm{~g} / \mathrm{d}$ of rat chow for 1 week until bodyweight was reduced to $85 \%$ of normal. During this time, rats were handled and had free access to water. After reaching optimal body weight, rats were trained to press a bar for food. We used bar-pressing to maintain a constant level of spontaneous activity so that freezing to the tone can be reliably measured during long sessions (Quirk et al. 2000; Santini et al. 2001). Rats were trained in a standard operant chamber $(25 \times 29 \times 28 \mathrm{~cm})$ situated in a sound-attenuating box that reduced ambient sound to $55 \mathrm{~dB}$ (Coulbourn Instruments). After $7 \mathrm{~d}$, rats learned to press in excess of $20 / \mathrm{min}$ on a variable interval schedule of reinforcement (VI-60).

After bar-press training, fear conditioning was administered in the same chamber, which was fitted with an electrifiable grid floor. A speaker was mounted on the opposite wall from the lever. Rats were conditioned four at a time, each in their own box. Food reward was continuously available on a VI-60 schedule throughout the experiment. The conditioned stimulus was a tone $(4 \mathrm{kHz}, 80 \mathrm{~dB}$ SPL, $30 \mathrm{sec}$ ), and the unconditioned stimulus was a scrambled footshock $(0.6 \mathrm{~mA}, 0.5 \mathrm{sec})$ coterminating with the tone. On d0, all rats received five habituation trials (tone alone) followed immediately by seven conditioning trials (tone plus footshock). After $1 \mathrm{~h}$ in the home cage, rats in the extinction groups were returned to the operant chamber for 20 extinction trials (tone alone). The intertrial interval varied between 2 to $6 \mathrm{~min}$, throughout. At the conclusion of $\mathrm{d} 0$, rats remained in their home cages for 0 to $14 \mathrm{~d}$, and then were given 15 additional extinction trials to test for spontaneous recovery of conditioned freezing (see Fig. 1). Rats were assigned to one of 7 groups, with post-extinction delays of $0 \mathrm{~d}(30 \mathrm{~min}, \mathrm{n}=7)$, $1 \mathrm{~d}(\mathrm{n}=11), 2 \mathrm{~d}(\mathrm{n}=10), 4 \mathrm{~d}(\mathrm{n}=7), 6 \mathrm{~d}(\mathrm{n}=8), 10 \mathrm{~d}(\mathrm{n}=6)$, or $14 \mathrm{~d}(\mathrm{n}=11)$. Two additional groups received conditioning only (no-extinction controls) and were tested for recall of conditioning after a delay of $1 \mathrm{~d}(\mathrm{n}=10)$ or $14 \mathrm{~d}(\mathrm{n}=9)$. A total of 79 rats were used.

Rat behavior was videotaped with digital video cameras (Microvideo Products). The percent time spent freezing during each tone (the absence of all movements except for respiration; Blanchard and Blanchard 1972) was measured from the videotape by observers blind with respect to group assignment. Freezing was analyzed in blocks of two trials. We compared three time points: (1) pre-extinction (first two trials of extinction on d0), (2) postextinction (last two trials of extinction on d0), and (3) spontaneous recovery (first two trials of extinction on the test day). The degree of spontaneous recovery of freezing on the test day was expressed as the percent rebound (Santini et al. 2001), which is the freezing on the test day divided by the pre-extinction freezing. Means for freezing and rebound were compared with ANOVA and Tukey HSD post-hoc tests, when appropriate (STATISTICA, Statsoft).

\section{ACKNOWLEDGMENTS}

We gratefully acknowledge the help of Tanvir Syed and Elsamarie Rosaly for training the animals and of Mohammed Milad for helpful discussions. This work was supported by NIH grants R29-MH58883 and S06-GM08239 to G.J.Q.
The publication costs of this article were defrayed in part by payment of page charges. This article must therefore be hereby marked "advertisement" in accordance with 18 USC section 1734 solely to indicate this fact.

\section{REFERENCES}

Blanchard, D.C. and Blanchard, R.J. 1972. Innate and conditioned fear reactions to threat in rats with amygdaloid lesions. J. Comp. Phys. Psychol. 81: 281-290.

Bouton, M.E. 1991. Context and retrieval in extinction and in other examples of interference in simple associative learning. In Current topics in animal learning: Brain, emotion and cognition (eds. L. Dachowski and C.F. Flaherty), pp. 25-53, Earlbaum, Hillsdale, NJ.

. 1993. Context, time, and memory retrieval in the interference paradigms of Pavlovian learning. Psychol. Bull. 114: 80-99.

. 1994. Context, ambiguity, and classical conditioning. Curr. Dir. Psychol. Sci. 3: 49-53.

Bouton, M.E. and King, D.A. 1983. Contextual control of the extinction of conditioned fear: Tests for the associative value of the context. J. Exp. Psychol. Anim. Behav. Process. 9: 248-265.

Bouton, M.E., Rosengard, C., Achenbach, G.G., Peck, C.A., and Brooks, D.C. 1993. Effects of contextual conditioning and unconditional stimulus presentation on performance in appetitive conditioning. Q. J. Exp. Psychol. B 46: 63-95.

Cain, C.K. and Barad, M. 2000. Massed training is superior to spaced training for extinction of fear conditioning in mice. Soc. Neurosci. Abstr. 26: 2245.

Falls, W.A., Miserendino, M.J.D., and Davis, M. 1992. Extinction of fear-potentiated startle: Blockade by infusion of an NMDA antagonist into the amygdala. J. Neurosci. 12: 854-863.

Fanselow, M.S. 1980. Conditioned and unconditional components of post-shock freezing. Pavlov. J. Biol. Sci. 15: 177-182.

Fanselow, M.S., and Gale, G.D. 2002. The amygdala, fear and memory. Ann. NY Acad. Sci. (in press).

Fendt, M. and Fanselow, M.S. 1999. The neuroanatomical and neurochemical basis of conditioned fear. Neurosci. Biobehav. Rev. 23: $743-760$.

Fisk, G.D. and Wyss, J.M. 2000. Descending projections of infralimbic cortex that mediate stimulation-evoked changes in arterial pressure Brain Res. 859: 83-95.

Gewirtz, J.C., Falls, W.A., and Davis, M. 1997. Normal conditioned inhibition and extinction of freezing and fear-potentiated startle following electrolytic lesions of medial prefrontal cortex. Behav. Neurosci. 111: 712-726

Herry, C. and Garcia, R. 2002. Prefrontal cortex long-term potentiation, but not long-term depression, is associated with the maintenance of extinction of learned fear in mice. J. Neurosci. 22: 577-583.

Herry, C., Vouimba, R.M., and Garcia, R. 1999. Plasticity in the mediodorsal thalamo-prefrontal cortical transmission in behaving mice J Neurophysiol. 82: 2827-2832.

Konorski, J. 1967. Integrative activity of the brain. University of Chicago Press, Chicago, IL.

Lattal, K.M. and Abel, T. 2001. Different requirements for protein synthesis in acquisition and extinction of spatial preferences and context-evoked fear. J. Neurosci. 21: 5773-5780.

LeDoux, J.E. 2000. Emotion circuits in the brain. Ann. Rev. Neurosci. 23: 155-184

LeDoux, J.E., Xagoraris, A., and Romanski, L. 1989. Indelibility of subcortical emotional memories. J. Cog. Neurosci. 1: 238-243.

Lee H. and Kim J.J. 1998. Amygdalar NMDA receptors are critical for new fear learning in previously fear-conditioned rats. J. Neurosci. 18: 8444-8445

Maren, S. 2000. Is there savings for pavlovian fear conditioning after neurotoxic basolateral amygdala lesions in rats? Neurobiol. Learn Mem. 76: 268-283.

Mast, M., Blanchard, R.J., and Blanchard, D.C. 1982. The relationship of

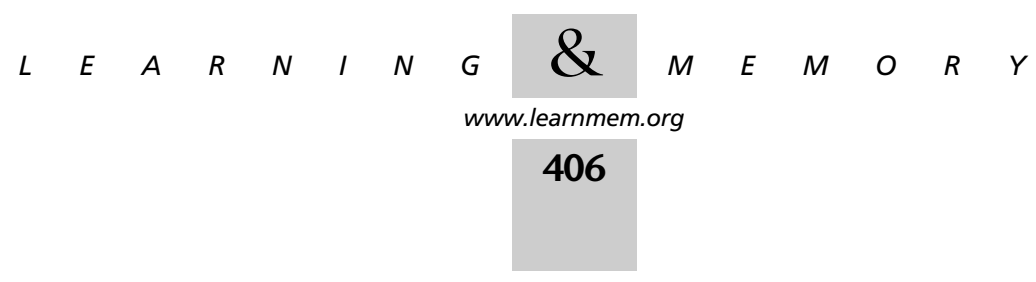


freezing and response suppression in a CER situation. Psych. Record 32: 151-167.

McDonald, A.J. 1991. Organization of amygdala projections to the prefrontal cortex and associated striatum in the rat. Neuroscience 44: $1-14$

McDonald, A.T., Mascagni, F., and Guo, L. 1996. Projections of the medial and lateral prefrontal cortices to the amygdala: A Phaseolus vulgaris leukoagglutinin study in the rat. Neuroscience 71: 55-75.

Milad, M.R., and Quirk, G.J. 2002. Neurons in medial prefrontal cortex signal memory for fear extinction. Nature (in press).

Milad, M.R., Rosaly, E., Syed, T., and Quirk, G.J. 2001. Full spontaneous recovery of extinguished freezing does not indicate loss of extinction memory. Soc. Neurosci. Abstr. 27: 743.12.

Morgan, M.A., Romanski, L.M., and LeDoux, J.E. 1993. Extinction of emotional learning: Contribution of medial prefrontal cortex. Neurosci. Lett. 163: 109-113.

Morrow, B.A., Elsworth, J.D., Rasmusson, A.M., and Roth, R.H. 1999. The role of mesoprefrontal dopamine neurons in the acquisition and expression of conditioned fear in the rat. Neuroscience 92: 553-564.

Ohman, A. and Mineka, S. 2001. Fears, phobias, and preparedness: Toward an evolved module of fear and fear learning. Psychol. Rev 108: $483-522$.

Pavlov, I.P. 1927. Conditioned reflexes. Oxford University Press, London, United Kingdom.

Quirk, G.J., Repa, C., and LeDoux, J.E. 1995. Fear conditioning enhances short-latency auditory responses of lateral amygdala neurons: Parallel recordings in the freely behaving rat. Neuron 15: 1029-1039.

Quirk, G.J., Armony, J.L., and LeDoux, J.E. 1997. Fear conditioning enhances different temporal components of tone-evoked spike trains in auditory cortex and lateral amygdala. Neuron 19: 613-624.

Quirk, G.J., Russo, G.K., Barron, J.L., and Lebron, K. 2000. The role of ventral medial prefrontal cortex in the recovery of extinguished fear. $J$. Neurosci. 20: 6225-6231.

Rescorla, R.A. and Heth, C.D. 1975. Reinstatement of fear to an extinguished conditioned stimulus. J. Exp. Psychol. 1: 88-96.

Rodriguez, B.I., Craske, M.G., Mineka, S., and Hladek, D. 1999.

Context-specificity of relapse: Effects of therapist and environmental context on return of fear. Behav. Res. Ther. 37: 845-862.

Rosenkranz, J.A. and Grace, A.A. 2002. Cellular mechanisms of infralimbic and prelimbic prefrontal cortical inhibition and dopaminergic modulation of basolateral amygdala neurons in vivo. J. Neurosci. 22: 324-337.

Royer, S. and Pare, D. 2002. Bidirectional synaptic plasticity in intercalated amygdala neurons and the extinction of conditioned fear responses. Neuroscience (in press).

Santini, E., Muller, R.U., and Quirk, G.J. 2001. Consolidation of extinction learning involves transfer from NMDA-independent to NMDA-dependent memory. J. Neurosci. 21: 9009-9017.

Teich, A.H., McCabe, P.M., Gentile, C.C., Schneiderman, L.S., Winters, R.W., Liskowsky, D.R., and Schneiderman, N. 1989. Auditory cortex lesions prevent the extinction of Pavlovian differential heart rate conditioning to tonal stimuli in rabbits. Brain Res. 480: 210-218.

Walker, D.L. and Davis, M. 2002. The role of amygdala glutamate receptors in fear learning, fear-potentiated startle, and extinction. Pharmacol. Biochem. Behav. 71: 379-392.

Walker, D.L., Ressler, K.J., Lu, K.T., Davis, M. 2002. Facilitation of conditioned fear extinction by systemic administration or intra-amygdala infusions of D-cycloserine as assessed with fear-potentiated startle in rats. J. Neurosci. 22: 2343-2351.

Received September 4, 2002; accepted in revised form September 18, 2002.

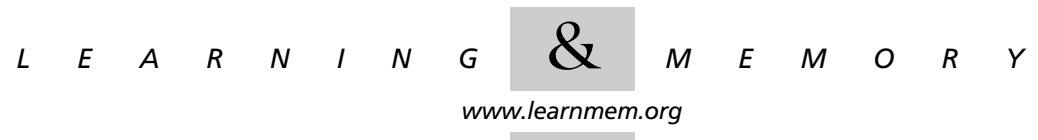




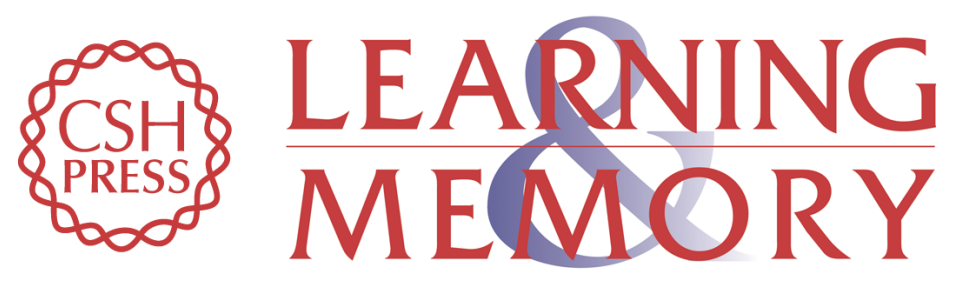

\section{Memory for Extinction of Conditioned Fear Is Long-lasting and Persists Following Spontaneous Recovery}

Gregory J. Quirk

Learn. Mem. 2002, 9:

Access the most recent version at doi:10.1101//m.49602

References This article cites 33 articles, 8 of which can be accessed free at:

http://learnmem.cshlp.org/content/9/6/402.full.html\#ref-list-1

License

Email Alerting Receive free email alerts when new articles cite this article - sign up in the box at the top Service right corner of the article or click here. 